\title{
Fundamentos filosófico-teológicos para una lectura teológica de la realidad según Hans Urs von Balthasar
}

\author{
Rodrigo Polanco ${ }^{1}$ \\ FACULTAD DE TEOLOGÍA \\ PONTIFICIA UNIVERSIDAD CATÓLICA DE CHILE
}

La teología práctica/pastoral puede definirse de diversas maneras ${ }^{2}$, pero en todo caso, es una reflexión creyente, individual y comunitaria, sobre la praxis y desde la praxis del Evangelio. Implica entonces una dialéctica ratiolfides-praxis. Un aspecto de esa tensión es lo que se llama lectura teológica de la realidad. ¿Cómo se fundamenta una lectura teológica de la realidad? La teología de Hans Urs von Balthasar nos da algunas claves importantes para encontrar un fundamento filosófico-teológico a diversos aspectos de la teología práctica/pastoral.

Pero, ¿existe una teología práctica/pastoral en Balthasar? Cuando se habla, en general, de teología práctica/pastoral, el nombre de Hans Urs von Balthasar normalmente no se evoca. Sin embargo su aporte es importante, no porque él escribiera alguna obra con un título explícito en ese sentido, tampoco porque encontremos en su gran síntesis teológica -su voluminosa Trilogía- alguna parte dedicada explícitamente a ese objeto, sino simplemente porque su teología, como tal, es considerada por él mismo, desde una perspectiva fundamental, como teología pastoral/ práctica, es decir, como reflexión del ser/actuar cristiano. Sin negar, por otra parte, que haya escrito obras que apuntan a objetos y metodologías explícitamente práctico/pastoral ${ }^{3}$. Su teología se interesa por la razón de

\footnotetext{
rpolanco@uc.cl
}

2 Cf. B. Kazmpf, «Conceptions et enjeux de la théologie pratique: entre aiguilles, aiguillages et aiguillons», en E. Parmentier (ED.), La théologie pratique. Analyses et prospectives (Presses Universitaires de Strasbourg, Strasbourg 2008) 11-34; M. VIAU, "De la théologie pastorale à la théologie pratique», en G. Routhier - M. Viau (ED.), Précis de théologie pratique (Lumen Vitae, Bruxelles 2007) 41-53.

3 Por citar solo dos clásicos: Schleifung der Bastionen. Von der Kirche in dieser Zeit (Johannes Verlag, Einsiedeln 1952); Glaubhaft ist nur Liebe (Johannes Verlag, Einsiedeln 1963). 
ser de la práctica cristiana/eclesial, sus fundamentos filosófico-teológicos y su condición de posibilidad para la humanidad. Desde una perspectiva crítica, hermenéutica y sistemática desarrolla el ser y la misión del cristiano en el mundo actual. El cristianismo -para él- es encuentro personal con Cristo, es llamada y elección de Dios, en correlación a la respuesta humana, entendida como obediencia existencial, es decir, como misión. Todo lo cual supone que Dios puede hablar al ser humano, y este puede comprenderlo, esto es, hay algo común entre ambos, algo que es común además a todo ser humano, en cualquier momento de la historia. Reflexión sobre el cristianismo, entendido como encuentro, comunicación y testimonio, es decir, como amor que se despliega en la vida, en cuanto respuesta a una Palabra divina, dicha a través de la carne, es simplemente -en la mente de nuestro autor- teología práctica/pastoral.

La teología de Balthasar (Lucerna 1905 - Basilea 1988), «tal vez el hombre más culto de nuestro siglo» -según palabras de Henri de Lubac $^{4}-$, no es fácil. Todavía se le conoce poco y, a veces, solo se conocen algunas caricaturas de su pensamiento. Difícil, no solo porque tiene una base filosófica muy amplia, sino porque también recurre a una amplia gama de pensadores, particularmente literatos y poetas, como formas teológicas verdaderas y sugerentes. Fue un escritor sumamente prolífico, que se interesó por una diversidad de temas, y en los años de madurez intentó una síntesis de su teología, entendida más como proyecto de forma teológica, que como síntesis a partir de los tratados clásicos ${ }^{5}$ Y en eso también está su dificultad: la diversidad de temas lo obligó, cada diez años, a hacer una guía de lectura de sus propias obras ${ }^{6}$. Y el proyecto de forma/estilo teológico, bien logrado, obliga al lector, sin embargo, a

H. De Lubac, Un témoin dans l'Église: Hans Urs von Balthasar, Paradoxe et Mystère de l'Église (Paris, 1967)184.186, citado por A. ScolA, Hans Urs von Balthasar: uno stile teologico (Jaca Book, Milano 1991) 27.

5 H. von Balthasar, Gloria. Una estética teológica, 7 vol. (Encuentro, Madrid 1985-1989); Teodramática, 5 vol. (Encuentro, Madrid 1990-1997); Teológica, 3 vol. (Encuentro, Madrid 1997-1998); Epílogo (Encuentro, Madrid 1998). Original alemán: Herrlichkeit. Eine theologische Ästhetik, Bd. I, II/1, II/2, III/1/i, III/1/ ii, III/2,i, III/2/ii (Johannes Verlag, Einsiedeln 1961-1969); Theodramatik, Bd. I, II/1, II/2, III, IV (Johannes Verlag, Einsiedeln 1973-1983); Theologik, Bd. I, II, III (Johannes Verlag, Einsiedeln 1985-1987); Epilog (Johannes Verlag, Einsiedeln 1987).

6 Cf. C. Capol, Hans Urs von Balthasar zu seinem Werk (Johannes Verlag Einsiedeln, Freiburg 2000) [Zu seinem Werk]. 
entrar en una nueva forma de pensar la teología, a partir de los padres y de Goethe .

Si miramos ahora su Trilogía -Gloria, Teodramática y Lógica-, encontramos en su misma estructura un elemento significativo para nuestro tema -lectura teológica de la realidad-, aunque en un cierto grado de abstracción, que es algo complejo penetrar. La estructura teológica de la realidad está fundamentada en los trascendentales del ser -belleza, bondad y verdad-, con lo cual se nos da un acceso a la comprensión de la realidad desde el misterio del ser. Pero el ser y los trascendentales del ser son, en sí, una integración del todo en el fragmento, lo cual fundamenta un acceso universal a la revelación histórica acaecida en Cristo. Y esta revelación tiene su centro en el drama-Teodramática- llevado a cabo por Cristo, en donde la identidad de su persona y misión resultan ser la clave hermenéutica para comprender, no solo su actuación, sino a toda vida humana, que ha de ser comprendida como misión. Densos temas que merecen ahora un pormenorizado estudio, el cual nos puede dar algunas claves preciosas para leer -desde el Evangelio/Cristo- la realidad, entendida como juego de libertades.

\section{EXISTIMOS, PERO PODRÍAMOS NO EXISTIR. EXPERIENCIA BÁsICA DEL SER}

Si comenzamos desde nosotros mismos, podemos hacer una reflexión básica: existimos, pero podríamos no existir. Entonces si existimos, pudiendo no existir, es porque alguien quiso que existiésemos: nuestros padres, la comunidad que nos ampara, finalmente, Alguien con mayúscula. Este es el maravilloso misterio de ser/existir, pero sin tener en nosotros el fundamento de nuestro $\operatorname{ser}^{8}$. Es la experiencia de la contingencia, de la limitación, que en todo caso, la vida se encarga de hacérnosla patente. Pero a la vez en esa misma reflexión están incluidas otras dos experiencias igualmente básicas. Por una parte la apertura a la totalidad, y por otra, la experiencia del amor gratuito. Revisemos ambos puntos.

En el hecho de nuestra contingencia -que existimos pero que podríamos no existir-, se revela una apertura a lo ilimitado, a todo ser, al hecho de que existe una realidad global. Muchas cosas que existen podrían no existir - no ser-, es decir, todo ente es limitado, pero el ser no lo es. El ser es «lo primero con que se encuentra el espíritu cognoscente». Es «lo más

7 Cf. C. Capol, Hans Urs von Balthasar zu seinem Werk, 112.

8 Cf. A. Scola, Hans Urs von Balthasar: uno stile teologico, 31. 
abarcador», pero a la vez, «lo totalmente indeterminado» ${ }^{9}$, porque existe solamente en los entes. «El todo de la realidad solo existe en el fragmento de un ente finito, pero el fragmento no existe más que por el todo del ser real» ${ }^{10}$. Esta es una distinción muy importante -entre ser y ente-, que Tomás llama distinción real, y que es el detonante de la pregunta por el sentido de las cosas y de uno mismo. Precisamente porque conozco mi finitud y, a la vez, experimento que el ser no es limitado, sino universal y omnicomprensivo, es que puedo preguntarme, de dónde vengo, a dónde voy, por qué existo. «Esta paradoja nos remite a un fundamento, que es tanto la esencia común de toda realidad, como también lo que tiene la subsistencia requerida para la delineación de todo ente» ${ }^{11}$. Ahora bien esta reflexión -muy abstracta- tiene, sin embargo, una consecuencia sumamente existencial: nada finito -yo mismo y todo ente- se ha dado la existencia a sí mismo, sino que «tiene como horizonte... un fundamento, al que se debe» ${ }^{12}$. En consecuencia, el contacto con la realidad-con el ser-con lo que es más común y pobre de todo, es lo que nos abre a la trascendencia. Ese es el modo como habla Dios y así ha de escuchar el ser humano. La realidad tiene consistencia. Es la recuperación del ser, que pedía Heidegger.

\section{El diÁlogo, EXPERIENCia básica DEL SER huMANo}

Volviendo ahora a la experiencia primaria de nuestra existencia, vemos que la polaridad que descubríamos en el ser/ente se encuentra también en la antropología. El ser humano existe necesariamente en diálogo con los demás. De hecho la primera experiencia que un niño tiene de sí mismo, cuando toma conciencia de sí mismo -como sí mismo distinto de lo demás-, es una experiencia doble: de sí mismo y de su madre como distinta de él. Pero, en ese mismo acto, percibe que su madre lo sostiene, le sonríe y lo ama. «El horizonte del Ser infinito en su totalidad se abre para él en el diálogo. Y, en el diálogo, correlativamente, el hombre adquiere conciencia de sí mismo»"13. La relación yo-tú es la que le abre el espacio del yo, simultáneamente con el espacio del ser. En la madre se le abre el tú $y$ el ser en tu totalidad, junto con tomar conciencia de sí mismo como individuo. $\mathrm{Y}$

9 H. von Balthasar, Epílogo, 45. Aunque a lo largo de este trabajo cito la traducción castellana, en numerosas ocasiones la he modificado a la vista del original.

10 H. von Balthasar, Epílogo, 47.

11 H. von Balthasar, Epílogo, 48.

12 H. von Balthasar, Epilogo, 50.

13 A. Scola, Hans Urs von Balthasar: uno stile teologico, 38. 
en ese encuentro se le revelan cuatro cosas: «1) que él es uno en el amor con su madre, al tiempo que no es su madre, por lo tanto que todo ser es uno; 2) que ese amor es bueno: por tanto, todo ser es bueno; 3) que ese amor es verdadero, por consiguiente, todo ser es verdadero; 4) que ese amor provoca alegría, por tanto todo ser es bello» ${ }^{14}$. Uno, bueno, verdadero y bello son los trascendentales del ser, que han sido descubiertos en el encuentro con el otro.

Estos trascendentales son propiedades que pertenecen al ser en cuanto tal y superan todos los límites de las esencias. Son atributos trascendentales del ser, es decir, atraviesan todo ser, son coextensivos al ser y son «interiores los unos a los otros: lo que es realmente verdadero, debe también ser bueno y bello y uno. Un ser aparece, resulta una epifanía: es bello y nos maravilla. Al aparecer se da, se nos entrega: es bueno. Y al entregarse se dice, se desvela a sí mismo: es verdadero (en sí y en el otro a quien se revela)» ${ }^{15}$. De modo que en el encuentro con el otro, se revela, además, el ser mismo en sus trascendentales. Es lo que Balthasar ha llamado meta-antropología. La importancia de esto es que tras el encuentro con el otro, se encuentra uno con el ser mismo, no con una imagen, ni con una simple esencia, sino con el ser en sus atributos. Esto nos habla de la densidad que posee todo encuentro: es comunicación abierta a la trascendencia. Balthasar extrae de aquí dos consecuencias: «El hombre solo existe por el diálogo interhumano, es decir, a través del lenguaje, la palabra (en gestos, mímica o vocablos). Entonces, ¿por qué negar al ser mismo la palabra? En el principio existía la Palabra, y la Palabra estaba junto a Dios, y la Palabra era Dios (Jn 1, 1)» ${ }^{16}$. Con esto queda puesta la razonabilidad de la hipótesis de la revelación. Si el ser en sus trascendentales es dialógico y en el hombre esta dialogicidad llega a su culminación (porque descubre quién es, precisamente en el diálogo), ¿podemos realmente negar un posible diálogo de Dios con el hombre? Sería contradictorio. Con todo, la respuesta definitiva solo la entregará la cristología que nos habla de la creación realizada en y por medio de la Palabra (Col 1, 15-20) ${ }^{17}$, pero el camino está ya esbozado, a la vez que afirmada la condición de su posibilidad.

La segunda consecuencia. "Si suponemos que Dios es verdaderamente Dios (esto es, la totalidad del ser que no tiene necesidad de ninguna creatura), entonces Dios es también la plenitud de lo uno, lo bueno, lo verdadero y lo bello. En consecuencia, la creatura limitada participará solo en parte, fragmentariamente, de los trascendentales» ${ }^{18}$. Esto implica

\footnotetext{
14 C. Capol, Hans Urs von Balthasar zu seinem Werk, 98.

15 C. Capol, Hans Urs von Balthasar zu seinem Werk, 99.

16 C. CAPOL, Hans Urs von Balthasar zu seinem Werk, 99.

17 A. Scola, Hans Urs von Balthasar: uno stile teologico, 40.

18 C. Capol, Hans Urs von Balthasar zu seinem Werk, 99.
} 
que en el campo de la contingencia, de la creación, la unidad, la bondad, la verdad y la belleza estarán siempre divididas y polarizadas: somos cada uno un individuo, pero a la vez parte de una especie. La unidad está dividida y polarizada en una tensión entre unidades. Y lo mismo ocurre con los otros trascendentales. La contingencia posee entonces como ley fundamental la polaridad. «Polaridad quiere decir estricto entrecruzamiento de los polos en tensión. En ninguna parte debería ser esto más evidente que en la polaridad del ser finito entre esencia y existencia ${ }^{19}$. Ahora bien, esta segunda consecuencia -la polaridad propia de lo creado-, nos abre a la comprensión del lenguaje del ser que expresa necesariamente una Palabra de Dios. Es lo que Balthasar ha intentado hacer con su proyecto teológico fundado en la analogía del ser, ya no en su abstracción, sino tal como se encuentra el ser concretamente en sus atributos trascendentales. Es la analogía de los trascendentales. Relacionando en una gran perspectiva dos miradas complementarias, Balthasar ha logrado desentrañar el lenguaje de la realidad, y así, de Dios: una perspectiva más existencial, a partir de las relaciones interpersonales; y otra más metafísica, a partir del desvelarse del ser en sus trascendentales, pero desde la aparición de lo bello.

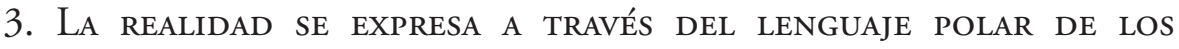 TRASCENDENTALES}

¿Cómo se da ahora esta manifestación -lenguaje- del ser -y de Dios- en la realidad? En el Epílogo de su Trilogía dedica densas páginas a resumir esta materia, que ya ha tratado a lo largo de sus 15 tomos anteriores ${ }^{20}$.

La realidad -el ser- proporciona a todo ente su ser-en-sí y, al mismo tiempo, su ser-con-otros, ya que la misma realidad de ser la comparten todos. Esto presupone en todo ente una capacidad interior de poder comunicarse, que no es otra cosa que compartir, partir-con-los-demás. Pues lo que se comunica se da, a la vez que se conserva, precisamente para poder darse. Todo ente posee el ser real que entraña una dualidad: por una parte, fundamenta al ente como ser-en-sí, y por otra, le permite salir de sí para realizarse a sí mismo en esa manifestación. Los entes reales se perfeccionan unos con otros. Pero el otro al manifestarse es siem-

\footnotetext{
19 H. von Balthasar, Teológica, I, 104.

20 Cf. H. von Balthasar, Epílogo, 43-80, que resumo en los siguientes párrafos.
} 
pre más que su manifestación, es justamente otro. Al mismo tiempo, se recibe al otro como otro y no como parte de uno. Se da precisamente salvaguardándose como otro. Aunque compartimos la esencia, sé que mi esencia no es su realidad. Este es el profundo misterio del ser: el problema de la unidad y polaridad del ser. La realidad -el ser- solo puede ser una (la uni-totalidad), pero no subsiste en sí, sino en una infinidad de entes y confiere a cada uno su unidad esencial, su ser individuos. Esta es la polaridad esencial del ser mundano que remite a una unidad fundamental, en donde los entes se entienden solo desde los otros y desde la totalidad. Las consecuencias de esta unidad trascendental son grandes. Es la necesidad del otro, como otro, para uno ser uno mismo, y es la validez de la palabra del otro, como otro, para la propia comprensión de uno mismo. Es la necesidad de la totalidad para ser uno mismo.

La reflexión continúa. "Todo ente mundano es epifánico, precisamente en la diferencia descrita». Se expresa a sí mismo justamente en la forma de su aparición. Es «una especie de lenguaje átono, pero no desarticulado, en el que las cosas no solo se expresan a sí mismas, sino también siempre a la realidad total presente en ellas, que (como non subsistens) remite a lo real subsistente ${ }^{21}$. Esta aparición suscita asombro, porque lo real desconocido puede mostrarse en una forma bella y perfecta, y porque esa belleza luminosa remite a la realidad que aparece en ella y que a la vez la trasciende. Esta es la polaridad de la belleza: es una luz que descansa en sí misma, y a la vez, una luz que trasciende la forma y señala un ser real que ilumina en ella. Y si para ser aparición, necesita de la indicación que hay en ella, entonces es epifanía. Ahora bien, el destinatario de lo bello, no recoge impresiones particulares, sino que puede leer formas como unidades, comprende totalidades en su aparición a partir de la profundidad. Es una suerte de veneración. Pero en eso está también la libertad de cada 'lector'. Frente al ser -la belleza- es posible una doble actitud, leerla como imagen, en sí misma significativa, o como aparición de aquello a lo que como imagen remite, que la abrirá a la realidad en sentido cabal. En toda belleza hay un momento de gracia: se me muestra más de lo que cabía esperar. Está abierta a la gracia y a la revelación de la gloria de Dios. Es el lenguaje epifánico que dice mucho acerca de la trascendencia y de la esencia del ser, a partir de la forma, como estructura unitaria hablante en la polaridad de forma y esplendor.

21 H. von Balthasar, Epílogo, 55. 
Hemos dicho que los trascendentales no pueden existir unos sin los otros. "Lo que se muestra (belleza), se comunica, se da (bondad). Y asimismo se manifiesta inmediatamente también (en un primer aspecto) que todo lo bueno del mundo posee también una estructura polar ${ }^{22}$. Bondad es lo que se busca en todas las cosas, aquello hacia lo que se tiende, ya que no solo cada ser humano, sino la totalidad de los seres apetece lo bueno. Todo ser apetece lo que necesita para existir, por lo tanto tiene también derecho a lo bueno. Todo ser humano tiene entonces derecho al amor, a la interrelación, que es el sumo bien. Pero eso mismo nos pone nuevamente en la estructura polar de la realidad, esta vez, entre el bien personal y el bien universal. Yo apetezco $m i$ bien, pero que está en relación y depende del bien de los demás, como también, el bien de la totalidad es mi propio bien, en una tensión siempre en un punto de equilibrio. Ahora, ¿cómo actúa el bien? Se regala, esa es su esencia. Pero, ¿cómo interactúa con la libertad personal?: Con el poder de la convicción, en cuanto reflejo del ser y, finalmente, reflejo del Logos. Su poder es el amor mismo, es la capacidad persuasiva, por la belleza y la bondad que le son inherentes, que remiten a su vez a la realidad total fundante, desde la propia individualidad consciente. Persuade en ese recóndito lugar en donde se juntan misteriosamente esta aparición bondadosa del ser y la propia autodeterminación.

Aquí queda patente el poder de la cruz, como amor que arrebata por su belleza-no-bella, pero que a la vez es gracia que llega a través del Espíritu. El Pneuma transforma nuestra voluntad en una comunión de voluntades porque «escribe su ley en nuestros corazones» (Jr 31, 31-34), es decir, nos hace querer el bien, nos comunica su voluntad. Es el mismo Hijo encarnado, como Logos creador, el que es la norma objetiva, pero que se comunica a nosotros como norma subjetiva a través del Espíritu. Se puede percibir la fuerza de esta presentación. El Hijo crucificado es la culminación de la realidad, que convence en y desde la realidad, por sí mismo, cuando la prescripción externa se convierte en inscripción en la misma libertad humana, por la fuerza de su realidad. La polaridad del ser -bondad- ha permitido el desarrollo del hombre hacia Dios. Y esto es válido para todo ser humano, en donde la bondad polar es el lenguaje de Dios.

22 H. von Balthasar, Epílogo, 63. 
La cumbre del desarrollo de la naturaleza se da cuando lo bello y lo bueno se pueden dar a conocer libremente desde su propia interioridad y autoconciencia: pueden decir-se. Y esta manifestación es a través del lenguaje, que es más que un simple expresarse en el aparecer. Es perfecta manifestación desde la interioridad libre y autoconsciente en gestos naturales, pero que a la vez son creativos y convenidos, a través de los cuales el sujeto da a conocer su propia interioridad. Pero también las formas todavía rudimentarias de belleza y bondad en la naturaleza son, de alguna manera, ya una palabra. Todo ser bello y bueno dice algo, a su modo. Pero esto supone que toda la realidad ha sido creada en la Palabra, responde a un Logos. Una vez más vemos que la entera «metafísica de los trascendentales del ser solo puede desarrollarse bajo la luz teológica de la creación del mundo en la Palabra de Dios» ${ }^{23}$. Todo esto nos está hablando de una fiesta del lenguaje, que nace de una fiesta del ser. Todo nos habla de Dios, pero hay que tener oídos para escuchar. La lectura teológica de la realidad necesita amor al ser, amor a la realidad, amor a la existencia y dejarse arrebatar por la realidad.

A partir de la polaridad estructural de la realidad, el lenguaje solo es posible si está abierto, en principio, a la autoconciencia del ser en su totalidad, a la realidad toda. Esto implica, a la vez, que la autoconciencia se comprende reflexivamente como ser o realidad y se comprende también como un ser que es más que la suma de los entes finitos que en él participan. El conocimiento supone así totalidad, esto es, comunidad. Igualmente si una persona en el diálogo quiere no solamente decir algo, sino entregarse a sí mismo -comunicarse-, entonces encuentra precisamente en la pobreza del lenguaje la posibilidad de hacerlo. El lenguaje ha presupuesto el conocimiento del ser como realidad y libertad de las palabras. Por otra parte, el sujeto descubre el ser, pero a la vez el ser se le descubre, se le regala, pero siempre desde el ente. Ahora bien, si los entes en el mundo no dependen originariamente en su realidad y verdad del juicio del espíritu humano, sino de la libre elección de un espíritu absoluto, libre (porque existen unas cosas y no otras, de las infinitas que podrían existir). Entonces queda claro que toda la realidad supone que hay un Espíritu absoluto de lo que depende todo el ser, pero también que la luz que le permite al hombre reconocer esa verdad del ser no le pertenece como propia, sino que también le fue regalada por esa Luz

23 H. von Balthasar, Epílogo, 72. 
absoluta. De modo que toda realidad cosmológica o existencial, por el hecho de existir, es lenguaje, tiene derecho a hablar, y solo en su escucha el mundo se desarrolla. La existencia es lenguaje de Dios.

\section{LA FORMA Y SU ESPLENDOR COMO LENGUAJE EXIMIO}

Retomando lo dicho, podemos afirmar que los tres trascendentales están íntimamente compenetrados los unos en los otros. En los tres habita una polaridad fundamental y esta deriva de la polaridad de la unidad que lo traspasa todo, la cual está a la base de todos los trascendentales. Esto nos pone frente a la pregunta por la Unidad una, idéntica en sí misma, absoluta, es decir, frente a la analogía del ser. Por una parte, la polaridad que traspasa todo lo finito debe superarse en lo absolutamente uno, verdadero, bueno y bello. Y por otra, esos trascendentales deben llegar a coincidir de tal modo entre sí en la Unidad una que se encuentren cada uno no disminuidos en los otros. Así pues en Dios su gloria/belleza es su autodonación/bondad y esta es su verdad. Pero esta identidad "presupone que Dios - más allá de la forma más elevada del ser del mundo, del ser del espíritu- es espíritu absoluto y, por consiguiente, libertad absoluta que se posee a sí misma». "Ahora bien, el poder-mostrar-se, regalar-se, decir-se de las cosas finitas no pertenece a su necesidad, sino a su perfección esencial del ser; debe, por esto, tener su prototipo en el ser divino» ${ }^{24}$. Estamos en las puertas de la teología, que es la culminación de la filosofía del ser. La polaridad remite a la Unidad, pero a la vez depende de esa Unidad. Muestra así cómo la analogia entis es el fundamento indispensable de toda lectura teológica de la realidad.

Sin embargo la analogia entis nos pone no solo frente a la pregunta por la Unidad-una, sino también frente a la pregunta por la estructura unitaria del ser. Esto es lo que Balthasar ha desarrollado con su concepto de forma, del cual ya hemos hablado y hemos extraído algunas consecuencias. Es importante, sin embargo, destacar en este concepto tan central para él toda la portada práxica que esta teología de la forma implica. Este concepto está referido, en última instancia, a la gloria de Dios, es decir, a la irradiación absolutamente libre y misteriosa, fascinante y asombrosa, de la grandeza de Dios, que se irradia a través del ser, de cada ente. Es una gloria que se expresa como belleza que arrebata a

24 H. von Balthasar, Epílogo, 79. 
quien la percibe. Pero a la vez la forma es igualmente la estructura concreta del ser (por lo tanto es algo interno y algo externo inseparablemente unidos), es su unidad que informa y traspasa todo. «Es una figura dinámica concreta que traspasa todo ente singular unificándolo en todas sus partes y lo abre al Ser que propiamente lo informa, le da forma y del cual es por lo tanto expresión, y lo hace capaz a su vez de irradiar su propio esplendor ${ }^{25}$. Y en el caso del hombre y del cristiano la forma se identifica con la existencia y con la existencia cristiana, con la historia. Es una suma/mezcla de forma y esplendor ${ }^{26}$. La forma se mide, el esplendor arrebata. Pero ambos se necesitan mutuamente y nunca se extinguen. Es, a la vez, una expresión y una impresión «que una forma con su esplendor ejerce sobre quien la percibe, el que a su vez, de alguna manera, es siempre arrebatado» ${ }^{27}$. La forma es belleza y es el lenguaje del Espíritu.

De este rico concepto, que nace de Goethe y que culmina en San Juan y que es la quintaesencia del pensamiento balthasariano, podemos comprender ahora mejor lo que para Balthasar es una lectura teológica de la realidad. Esto significa que «Dios no viene primeramente como maestro para nosotros (verdadero), como redentor completamente abocado a nuestro bien (bueno), sino para mostrarse e irradiarse a Si mismo, la gloria de su eterno amor trinitario, en aquella ausencia de interés propio que el verdadero amor con la verdadera belleza tiene en común ${ }^{28}$. La gloria corresponde en el plano teológico, a lo que en el plano filosófico es la belleza. Pero la belleza es la propiedad que asume universalmente todo el ser, su última fuerza irradiante, aquello por amor del cual en última instancia se ama. Y a través de ella irrumpe la presencia de Dios en todo ser. Es una concepción sumamente dinámica de la realidad, entendida como historia, intercambio, comunicación que expresan una unidad interna reflejo de la gloria de Dios. Leer la realidad es aprehender esa maravillosa unidad, esa arrebatadora presencia del misterio en el ser.

Este modo de comprender la presencia y palabra de lo divino es el único modo que le hace justicia a Dios, porque lo comprende y lo busca por sí mismo y no a partir de razones utilitarias dirigidas hacia el cosmos. Esto implica también que lo primero en la existencia de la realidad no

\footnotetext{
25 A. Scola, Hans Urs von Balthasar: uno stile teologico, 52.

26 Cf. H. von Balthasar, Gloria, I, 21-35.

27 A. Scola, Hans Urs von Balthasar: uno stile teologico, 14.

28 C. Capol, Hans Urs von Balthasar zu seinem Werk, 68.
} 
es el dominio del otro, sino la actitud de servicio, de contemplación hacia el otro, de escucha. Mediante la veneración del ser se comprende lo inefable del amor divino, pero también lo sagrado de todo ser y de toda historia. Y la teología pastoral/práctica será simplemente una manifestación de la gloria de Dios como forma de expresión. «El contenido, o forma interior, es ya por sí misma gloria divina mundanamente manifestada que informa la forma externa y el estilo, los cuales, a pesar de mantener la libre creatividad humana, se mantienen gracias a aquel contenido ${ }^{29}$. Hay entonces una concordancia de contenido y forma, en sintonía con la realidad, con la historia y con todo lo humano; como hay concordancia en toda la realidad entre contenido y forma. La teología pastoral/práctica es una obediente reproducción de la impresión que deja la revelación, a la vez que una creativa y filial posibilidad de coexpresión comunitaria de ese misterio en el Espíritu Santo.

\section{INTEgRACiÓn DE LO OTRO EN Dios}

La lectura teológica de la realidad supone también una clave hermenéutica. Es Cristo. Antes de entrar en ese tema específicamente, es bueno tomar conciencia de que Cristo es una posibilidad que se ofrece dentro de mucha otras ${ }^{30}$. Es una oferta. ¿Por qué seguirlo a él? De acuerdo al principio el que ve más verdad, tiene más profundamente razón, aquellas visiones que abarcan menos podrían integrarse dentro de otras que abarcan más. Es la doctrina de los logoi spermatikoi. Pero ese método, aunque importante, no puede conducir por sí solo al objetivo. Con todo, el tema de la integración está en el fundamento de la realidad: el todo del ser se realiza en el ente, en cada ente, en todo ente. Es otra forma de ver la polaridad estructural del ser. Del todo en el fragmento.

La filosofía, desde su origen, se "había planteado la cuestión del fundamento, del ser, del sentido y de la finalidad de la existencia en general ${ }^{31}$. Y las religiones siempre han intentado dar una respuesta a esas interrogantes, al sentido último del mundo y de la existencia humana. Por lo tanto incluyen en sí la pregunta filosófica. Es verdad que la ciencia empírica actual -y su consecuencia, el positivismo- carece de la

\footnotetext{
29 A. Scola, Hans Urs von Balthasar: uno stile teologico, 15.

30 Para lo que sigue, expongo algunas ideas de H. von Balthasar, Epilogo, 15-40.

31 H. von Balthasar, Epílogo, 19-20.
} 
pregunta metafísica, sin embargo, toda antropología que subyace a una ciencia, no puede sustraerse al tema del sentido de la existencia. Ahora bien, «la pregunta verdaderamente filosófica por el sentido del ser en su totalidad, llevada a su culmen en el hombre, se convierte en la pregunta religiosa por su salvación total» ${ }^{32}$. La respuesta a esa interrogante fundamental acerca del sentido de la existencia, que se comprende como salvación total, puede asumir las más diversas formas.

A lo largo de la historia, la representación del sentido salvífico en el hombre -o de la salvación- ha adquirido, sin duda, una forma dualista. Incluso los monismos más extremos conllevan en sí una negación, porque al juzgar la realidad como apariencia, o como lo que debe ser rechazado, muestran que en última instancia nuestra realidad es simplemente no-ser frente al ser único al que hay que aspirar. «Todos los sistemas monistas que de algún modo quisieron superar el dualismo (ya sea apariencia o tragedia o ambas cosas), presente como dato originario, intentaron sobrepasar un abismo insuperable, aunque comprendieron con razón que un dualismo que permanece abierto equivale a un fracaso de la cuestión filosófico-religiosa» ${ }^{33}$. En las religiones se expresó esta perplejidad, o negando la posibilidad de acercamiento, o negando el irrenunciable momento de la distancia. Todo esto quiere decir que existen muchos logoi spermatikoi en las religiones, en donde unos integran elementos de otros, pero la integración entre ellos en lo decisivo ha permanecido siempre imposible, porque sus postulados, que aparentemente se excluyen, han permanecido enfrentados hasta el final, de tal manera que sus postulados no pueden ser abarcados en una sistema metafísico superior ${ }^{34}$.

Si miramos ahora las religiones reveladas, cuyos datos no vienen a reemplazar a la razón, comienzan siempre con una voz, que no pretende ser respuesta a la pregunta suprema del hombre, sino que invita a la obediencia y realiza una promesa ${ }^{35}$. La relación establecida es calificada como alianza, entendida como obra de una benevolencia enteramente libre de un Dios sobre el cual no hay ninguna anticipación. La alianza queda libremente fundada desde arriba. El judaísmo y el islam conservaron siempre el monoteísmo como religión de un Dios máximamente libre y

\footnotetext{
32 H. von Balthasar, Epílogo, 23.

33 H. von Balthasar, Epílogo, 28.

34 Cf. H. von Balthasar, Epílogo, 29.

35 Cf. H. von Balthasar, Epílogo, 29.
} 
personal, en donde se elimina conscientemente todo puente entre Dios y el hombre, que no sea un directo actuar libre de Dios en inspiración o milagro. Es la negación de toda teología práctico/pastoral. La llegada del cristianismo trajo una sorpresa en el monoteísmo: la encarnación (hasta la cruz) y la trinidad de Dios implicada en ella. Cristo, como Palabra de Dios hecha carne, y Dios, como amor trinitario. Ambos considerados como un absurdo y una abominación por judíos y musulmanes ${ }^{36}$.

Con esto vemos que «los axiomas fundamentales de una concepción del mundo y de una religión pueden valorarse de manera tan distinta que, sobre la base del principio de integración, no es posible una apologética puramente racional de la fe cristiana ${ }^{37}$. Sin embargo no es del todo inconducente ese principio, ya que nos podemos preguntar si acaso el cristianismo tiene en sí mismo una capacidad integradora en lo que toca a los axiomas fundamentales de las otras religiones. Y esa es otra clave esencial para comprender a Von Balthasar, no se trata de una comparación aséptica entre propuestas, sino que frente a la aparición histórica del cristianismo y a su respuesta mediante la fe obediente, nos preguntamos cómo en su esencia fundamental se integran las columnas básicas de toda otra propuesta y se superan los abismos insalvables de otras filosofías. El que integra más, ve más, y es más creíble.

«Los cristianos pronuncian un gran sí a las dos columnas fundamentales del judaísmo y del islam. La distancia insuprimible entre Dios y la creatura (la última es creación de la omnipotencia libre de Dios) y la acogida de una autorrevelación de Dios distinta de la creatura, por amor gratuito». Pero además tienen una respuesta frente a la «incomprensibilidad de cómo un ser finito puede poseer valor definitivo y dignidad suprema junto al Dios que lo es todo (o Absoluto) ». En el fondo la pregunta que no estaba resuelta era acerca de cómo comprender que la creación no es una necesidad en Dios. «El cristianismo supera tal inseguridad mediante su afirmación central de que Dios, para obtener el nombre de amor, quiere ser en sí mismo entrega y fecundidad y, por tanto, conceder espacio al otro dentro de su unidad, de modo que esto positivamente otro justifica el ser otro de la criatura frente a Dios y el otro en Dios, sin renunciar a la diferencia Dios-criatura, puede ser también este

\footnotetext{
36 Cf. H. von Balthasar, Epílogo, 33-34.

37 H. von Balthasar, Epílogo, 35.
} 
otro en la creaturalidad ${ }^{38}$. Es la Trinidad como axioma fundamental del cristianismo, y como fundamento indispensable de la encarnación y de la creación. En realidad solo este fundamento puede justificar definitivamente los axiomas básicos del judaísmo y del islam.

Con la aceptación positiva del otro se llenan además otros vacíos dejados por las religiones y la historia de la humanidad. El sujeto espiritual y creado gana la insuprimible dignidad de persona, a imagen de las relaciones divinas. El interlocutor primario de Dios no es ya el pueblo considerado como un todo, sino que en ese pueblo y desde ese pueblo, cada individuo alcanza su suprema dignidad por ser hermano de Cristo, interlocutor del Padre. Y luego el vacío del sufrimiento y la muerte -elementos esenciales de la existencia finita y sin respuesta satisfactoria en cualquiera otra propuesta religiosa- gana un sentido eminentemente positivo dentro del ser, al ser comprendido como «la suprema demostración de que Dios es amor, porque Cristo en la cruz, al revelar en sí el amor de Dios, toma sobre sí el pecado del mundo y lo sepulta en su muerte» ${ }^{39}$. De ser verdad eso, la misma muerte es aquí la manifestación extrema y la acción significativa y fecunda del amor. "Con esto se integra también positivamente lo que, en la experiencia de la variabilidad, de la fugacidad y transitoriedad dentro de la existencia terrena, apareció como una cosa negativa $»^{40}$, y en donde la antigua renuncia al mundo se transforma en disponibilidad para la misión y sumergirse en todo lo diferente ordenado por Dios, con plena percepción y experiencia de la diferencia, siguiendo el modelo de Cristo. Finalmente en Cristo resucitado en su carne se integra lo otro del ser del mundo dentro de Dios, de tal manera que la salvación no es ya salvación de la finitud, sino asunción de los finito (y, por eso, otro) en lo infinito, Cristo.

Todo esto sigue siendo un misterio y no puede ser construido o postulado a partir del mundo. Se acepta y obedece como palabra definitiva de Dios, pero en esa obediencia se confirma la misma obediencia existencial asumida, gracias a la capacidad integradora de los distintos aspectos de la propia existencia y de la realidad creada que posee esa nueva forma de existencia. Podemos ver entonces que toda lectura teológica de la realidad tendrá que ser integradora de lo otro, esto es, de todo otro

38 H. von Balthasar, Epílogo, 35-36.

39 H. von Balthasar, Epílogo, 37. Cf. Ibíd., 36-37.

40 H. von Balthasar, Epílogo, 37. 
creado, y además, ser conforme a la forma interior y exterior de la revelación cristiana, que es el paradigma de la integración de lo otro, al venir de Dios mismo. Toda palabra del otro y su propia dignidad nacen de la existencia del otro en Dios, expresado en Cristo muerto en la cruz. Eso nos da paso al último tema que es la cristología, como clave interpretativa de la realidad.

\section{ANALOGIA ENTIS CRISTOLÓGICA}

La teología balthasariana tiene como fuente y horizonte último a Cristo, id quo maius cogitari nequit. Toda filosofía encuentra su respuesta última en el Resucitado. El fundamento de este pensar teológico está en la superación de un pensar extrínseco en la relación entre naturaleza y gracia. «La gracia no denota algo que habría sido agregado al hombre ya completo, sino la forma como el hombre es definitivamente sí mismo» ${ }^{41}$. Y esto es así debido a que la creación ha sido hecha precisamente en Cristo (Col 1, 15-20). Entonces el hombre-imagen de Dios- encuentra realmente solo en Cristo su verdadera forma. Además Dios se revela en Cristo y Cristo, a su vez, es la verdadera exégesis del Padre. Y como ya hemos visto, todo eso solo es posible porque al interior de la Trinidad se da también lo otro ${ }^{42}$. Ahora bien, lo singular e irrepetible de Cristo es que su humanidad es el lugar en donde la Imagen perfecta del Padre -el Hijo y Logos-, sin dejar de ser la Imagen, se traspasa a la imagen creada -el hombre-. Es así el Hijo hecho carne. De esta manera la humanidad de Cristo es la humanidad del Hijo de Dios - por quien todo fue hecho-, y por lo tanto, la forma perfecta de lo humano. Y todo esto solo es posible, nuevamente, porque Jesucristo es la Palabra del Padre, la originaria autocomunicación del Padre, cuya acogida está abierta a los hombres por obra del Espíritu Santo. El principio de la humanidad no es Adán sino Cristo, pero incluso no simplemente el Logos, sino Jesucristo muerto y resucitado. En Cristo llega entonces a su ápice la analogia entis, y por lo tanto, para los seres humanos, él es el camino de acceso privilegiado a Dios y la medida exacta de cómo ha de ser la relación de Dios con los hombres ${ }^{43}$.

\footnotetext{
41 A. Scola, Hans Urs von Balthasar: uno stile teologico, 62.

42 Cf. A. Scola, Hans Urs von Balthasar: uno stile teologico, 64.

43 Cf. H. von Balthasar, Teodramática, III, 143-239; A. Scola, Hans Urs von Balthasar: uno stile teologico, 65-66.71-73.
} 
Continuando con la reflexión, para Balthasar el dato privilegiado de toda su cristología es el concepto de misión. Si, con Santo Tomás, la teología ha afirmado que las procesiones (=personas) divinas se descubren en las misiones extradivinas, de tal manera que la misión del Hijo y la misión del Espíritu en la economía divina nos muestran, precisamente, la existencia intradivina del Hijo y del Espíritu del Padre, entonces la coincidencia de persona y misión en Cristo es un dato irrefutable. El enviado se sabe idéntico a su misión, como enviado. Cristo no ha recibido una misión como dato secundario, sino que es el enviado ${ }^{44}$. Jesús es el Hijo de Dios generado por el Padre, "porque si el enviado tiene que revelar esencialmente el amor del que lo envía, y si es idéntico con su misión divina, entonces debe, en cuanto responsable personal de esta misión de amor, ser el fruto divino, es decir, eterno, del que envía y al que él mismo, en su sentido eminente, llama su Padre» ${ }^{45}$. Coincidencia de identidad (=persona) y misión. Esto no solo nos muestra un elemento trinitario-teológico, sino profundamente humano y existencial: la persona es su vocación, su misión. Precisamente porque el cristiano -y el ser humano en general- es un elegido y un llamado, su ser y su existencia son una vocación, por lo tanto, una historia a ser vivida. Para Balthasar solo la misión hace al sujeto espiritual una persona, porque solo la misión entrega a cada ser humano la singularidad que le es propia y que lo caracteriza como ser humano ${ }^{46}$. «La persona, por lo tanto, propiamente hablando, es solo teológica» ${ }^{47}$.

La misión de Cristo se desarrolla como teodramática, es decir, como acción y confrontación entre la libertad de Dios y la libertad del hombre. Esa lucha entre libertades es precisamente lo que confiere a la vida humana el carácter de Teo-drama, y en esa misma acción dramática se desvela paulatinamente el verdadero rostro de la Misericordia que ilumina toda existencia. Aquí entra en juego una nueva identificación, la coincidencia entre contenido del testimonio y forma del que testimonia. El contenido determina la forma, la cual expresa por su estructura interior y su iluminación exterior la cualidad de su contenido luminoso.

\footnotetext{
44 Cf. H. von Balthasar, Teodramática, III, 143-189.

45 H. von Balthasar, Teodramática, III, 476.

46 Cf. H. von Balthasar, Teodramática, III, 190-205.

47 A. Scola, Hans Urs von Balthasar: uno stile teologico, 94.
} 
Ahora frente a la pregunta acerca de cómo un acto histórico contingente -la vida de un hombre- puede tener un valor definitivo, universal y necesario, responde con una reflexión sobre el anuncio escatológico de la llegada del reino de Dios. Jesús anuncia la llegada del reino con palabras y acciones, cada una contingente y acotada, pero todas juntas apuntando prolépticamente hacia su pasión, como la expresión máxima de su amor definitivo y total, divino y escatológico. Todo lo cual supone, una vez más, que en ese hombre actúa verdaderamente el Hijo hecho carne. Sus actuaciones son acciones y palabras del Logos del Padre hecho carne por mediación del Espíritu del Padre. Y después de la pascua, los discípulos de Jesús reciben ese mismo Espíritu del Resucitado, Espíritu escatológico, de modo que pueden participar ya ahora de la situación escatológica iniciada con Jesús en cada una de sus acciones que han sido realizadas en y por el Espíritu de Pentecostés. Se trata de la nueva existencia en Cristo, de la cual San Pablo nos ha hablado con tanta lucidez. Es la escatología ya, pero todavía no. Esto hace que la soteriología no sea un apéndice de la cristología, sino la vida misma de Jesús, pero apuntando siempre hacia la cruz, como expresión suprema del amor de Dios por nosotros $^{48}$.

Y aquí está el último paso, el pro nobis. Es el punto central ${ }^{49}$. Se da aquí la conjunción de dos verdades, por una parte, que Jesús anuncia y realiza el perdón gratuito para todos, pero por otra, que nadie puede ser forzado a aceptarlo. Aquí tiene lugar el misterio de la cruz comprendido como ese maravilloso cambio de puesto de Cristo en lugar nuestro. En qué sentido la muerte de Cristo puede salvarnos sin que eso anule nuestra libertad, ya que no somos un simple objeto a rescatar, es el núcleo del misterio que intenta revelar. En realidad Dios sí puede salvarnos, pero debemos hacer propia esa salvación. Cuatro momentos lo explican. 1. El Verbo de Dios, al entrar en la naturaleza humana -Verbum caro factum est-, por su dignidad de Logos creador obtiene un puesto que altera a toda la naturaleza humana: se hace cabeza de la humanidad (Ef 1, 10). De esa manera se apropia de nuestra naturaleza caída, pero transformándola en lo que es en verdad: dolor de la alienación. 2. Puesto que Jesús es el Verbo, por quien todo fue hecho, entonces el ser, como actus completus

48 Cf. H. von Balthasar, Teodramática, III, 118-141.

49 Lo resumo a partir de las palabras finales de H. von Balthasar, Epilogo, 112-117.

Cf. H. von Balthasar, Teodramática, IV, 209-292. 
non subsistens -que se realiza siempre en el individuo/ente-, es ahora asumido por el Verbo en su individualidad/ente (=su humanidad particular), de modo que asume todo en sí (=el ser), incluida la alienación actual del hombre. Pero la supera al infinito ya que solo el Hijo, «que conoce al Padre tal cual es» (Jn 11, 27), puede sufrir la alienación de manera absoluta, como amor absoluto. 3. Pero la encarnación y la cruz son algo obrado por el Espíritu del Padre y del Hijo -el Espíritu Santo vendrá sobre ti (Lc 1, 35)-. El Espíritu es el entre el Padre y el Hijo, y por tanto, en la cruz dilata al máximo la separación como expresión de su unión. Y desde la cruz es donado al hombre para que entre en contacto con la libertad finita del hombre, en donde dice sí o no. $Y$ «desde este punto fontanal, el Espíritu, tal como ya se insinuó, confronta la libertad finita y deficiente consigo misma y le muestra cómo podría ser libertad que se realiza verdaderamente» ${ }^{50}$. Esto es, la confronta con lo que debería ser verdaderamente, al enfrentarse con la imagen del crucificado, que es la imagen del verdadero hombre, es decir, la verdadera imagen de esa libertad finita. Solo queda preguntarse si esa libertad está sosegada para captar esa imagen, que es volverse a sí mismo y a Dios al mismo momento. 4. «El sí o no de la libertad finita a la solicitación del Espíritu en su fundamento. Aquí acaba todo saber humano " ${ }^{51}$. Pero el evangelio nos da el derecho y nos pone la obligación de esperar contra toda esperanza (cf. Rom 4, 18), porque Dios, que es amor (1Jn 4, 8), quiere que todos los hombres se salven y lleguen al conocimiento de la verdad (1Tim 2, 4).

\section{Palabras de síntesis}

La lectura teológica de la realidad está inscrita en la más profunda dialéctica creacional y redentora entre Jesucristo y la humanidad, en una unidad dual o polaridad estructural superable solo en la escatología. La teología pastoral/práctica es entonces una dialéctica muy fina entre el ser, la realidad toda, entendida como forma, es decir, como la vida humana en sus expresiones vitales e históricas que hablan del ser y, a través de él, de la gloria inefable de Dios; y el Logos hecho carne y muerto en la cruz, como expresión de amor y sufrimiento vicario por nosotros, que nos dice quién y cómo es Dios, cuál es su amor y qué nos ofrece, para que nuestra vida sea cumplida. En ese diálogo íntimo y fecundo toda la

\footnotetext{
50 H. von Balthasar, Epílogo, 116.

51 H. von Balthasar, Epílogo, 116.
} 
realidad habla, porque participa del Logos hecho carne, pero de tal manera que su cruz es su clave hermenéutica. No todos la conocen explícitamente, pero los que sí la conocemos tenemos una misión insustituible, regalo de su misericordia, de la cual no nos es lícito desertar. 
Resumen: La teología de Von Balthasar, de manera implícita, da muchas claves para una teología pastoral o práctica. A partir de la experiencia básica del ser -la distinción entre ser y ente- y del ser humano -descubrimos nuestra individualidad al tiempo que descubrimos nuestro ser comunitario-, Balthasar desarrolla una teología de la analogía de los trascendentales del ser, que muestra la capacidad básica de la realidad de expresar la gloria de Dios. Pero esta capacidad de la realidad se basa, a su vez, en que la creación es obra del Logos, que luego se hace carne; y más hondamente aún en que en Dios existe lo otro de sí, en el Verbo divino. Es la analogia entis cristológica la que fundamenta la forma -o estructura concreta del ser- como expresión de la gloria de Dios, la que fundamenta la posibilidad de una lectura teológica de la realidad. El artículo muestra muy bien cuáles pueden ser los fundamentos filosóficos y teológicos para poder realizar una lectura teológica de la realidad.

Palabras clave: Balthasar, teología práctica, teología pastoral, analogia entis, trascendentales del ser.

Abstract: Implicitly, Von Balthasar's theology offers many keys for a practical or pastoral theology. From the basic experience of being, the distinction between being and a being, and of a human being, we discover our individuality at the same time as we discover our communal being. Balthasar develops a theology of the transcendence of being that shows us the basic capacity of reality to express the glory of God. But this capacity of reality is based, in turn, on creation being the work of Logos, who becomes flesh, and even more deeply in God existing in the other self, in the Divine Word. It is the christological entis analogy which supports the form (or the concrete structure of being) as an expression of the glory of God, which supports the possibility of a theological reading of reality. The article shows very well what the philosophical and theological foundations could be for being able to carry out a theological reading of reality.

Keywords: Balthasar, practical theology, pastoral theology, entis analogy, transcendence of being 